\title{
Gamification Framework for Software Development Project Processes
}

\author{
Valerija Platonova \\ Information Technology Institute \\ Riga Technical University \\ Riga, Latvia \\ valerija.platonova@edu.rtu.lv
}

\author{
Solvita Berzisa \\ Information Technology Institute \\ Riga Technical University \\ Riga, Latvia \\ solvita.berzisa@rtu.lv
}

\begin{abstract}
Gamification methodology has a positive impact on software development (SD) processes, contributes to better product quality production and team involvement. To show how gamification can be used to motivate the SD project team to carry out daily routine activities and document it in PM tool the gamification framework is proposed in this paper. With this gamification framework is also tried to solve project manager challenge to get actual information in PM tool entered by the project team for correct reporting of project status and process overview. A prototype of a gaming tool has been developed, which is based on Jira's app functionality and is implemented as a plugin.
\end{abstract}

Keywords-Software development project, gamification, project management, project team motivation.

\section{INTRODUCTION}

Information technology (IT) software development (SD) project is a complicated process involving many participants, tools and processes [1]. Participants motivation and opportunity to work for the team is often one of the crucial moments for the successful completion of the project [2]. In SD project also is a lot of daily routine tasks that are not so interesting, but it needs to be done. One of the routine tasks is updating information in PM tool (progress, time spent) that is critical for a project manager to understand tasks and project progress. Timely available information can help the project manager correctly report status, identify risks, issues and changes necessary to achieve successful project results [3].

Many changes are made in corporate culture to build the best atmosphere for resources and increase motivation at work, e.g. working from home, flexible working hours. One change that is made is adding gamification element at work [4], [5] that allow changing process and behaviours [6]. Best practices of gamification say that the best way of using gamification in the corporate field is gamification tool usage [7], [8]. Also, in SD processes are some attempts to gamify some processes, e.g., development and testing [9].

The objective of the research is to develop a gaming framework for SD project with a target to motivate the
SD project team to carry out daily routine activities and document it in PM tool. To identify requirements of the gamification framework has been reviewed the everyday life of the developer team and PM tool usage. A prototype of the gamification tool has been created based on the proposed framework and developed as a Jira plugin. The tool evaluation was carried out with focus group assessment.

The rest of the paper is structured as follows: Section 2 presents the research background of gamification and SD project daily tasks. Overview of the SD gamification framework is described in Section 3. The prototype of the gamification tool and its evaluation is given in Section 4. Conclusion and future work is presented at the end of the paper.

\section{RESEARCH BACKGROUND}

As the background of this research is SD project team daily tasks (Section II.A.) that can be gamified to improve team motivation and data quality in PM tool and theory about gamification framework (Section II.B.).

\section{A. SD project daily tasks}

The tasks of software developers are to develop or maintain a software unit according to specific customer requirements, within the limits of time and budget [1]. SD process consists of certain stages, such as design, development, documentation, testing and maintenance, with the goal of developing the final product [1]. This process is defined for the chosen SD project lifecycle model that creates a difference in team composition, processes, work units, and routine tasks [1]. In general points, SD project team can be divided into three roles programmers, analysts and testers and its main daily tasks have been summarised ([1], [10]policies, and operations of an organization, and to recommend solutions that enable the organization to achieve its goals. Business analysis involves understanding how organizations function to accomplish their purposes and defining the capabilities an organization requires to provide products and services to external stakeholders. It includes the definition of organizational goals, understanding how 
those goals connect to specific objectives, determining the courses of action that an organization has to undertake to achieve those goals and objectives, and defining how the various organizational units and stakeholders within and outside of that organization interact. A Guide to the Business Analysis Body of Knowledge (BABOK Guide, [11]) in Table I.

Additional to daily tasks all project team, in the same way, is involved in PM activities [3]. The first, project planning [1] - estimating, tasks planning, risk identification etc. The second, project status reporting [1] - tasks progress, how many time is spent, problems etc. In most cases, some PM tool is used for status reporting. One of the project manager challenges is getting correct information from PM tools that is crucially dependent on the project team entered information. In the same time status updating in PM tool has been classified as one of the monotonous routine tasks for the project team.

TABLE I. SD PROJECT ROLE DAILY TASKS

\begin{tabular}{|l|l|}
\hline \multicolumn{1}{|c|}{ Role } & \multicolumn{1}{c|}{ Activities } \\
\hline Programmer & $\begin{array}{l}\text { Develop new functionality } \\
\text { Testing } \\
\text { Fix defects } \\
\text { Code review }\end{array}$ \\
\hline Analyst & $\begin{array}{l}\text { Requirement definition and analyses } \\
\text { Change request analysis and commenting } \\
\text { Defect registering and analysis } \\
\text { Testing } \\
\text { Documentation writing } \\
\text { Support for programmers/testers }\end{array}$ \\
\hline Tester & $\begin{array}{l}\text { Manual and automated testing } \\
\text { Defect register } \\
\text { Retesting of defects } \\
\text { Test case writing }\end{array}$ \\
\hline
\end{tabular}

\section{Gamification}

Gamification is the use of game mechanics and elements in a non-game context [6]. The existing process is selected, and the game mechanics are used to motivate participation, increase engagement and loyalty [5]. To play the game, need to use certain elements of the game. Playing elements are divided into three components as indicated in Fig. 1 [12]:

- Dynamics - it can be described as the most important element of the game or "grammar" like emotional effects, a logic of events, a chronology of activities, an interaction between participants.

- Mechanics - these are the processes that prevent the game from moving forward - challenges, opportunities, co-operation and interactions, feedbacks, bonuses, game resources, etc.

- Components - these are the individual elements of mechanics and dynamics that interact, including points, roles, levels, avatars, winning tables, ratings, etc.

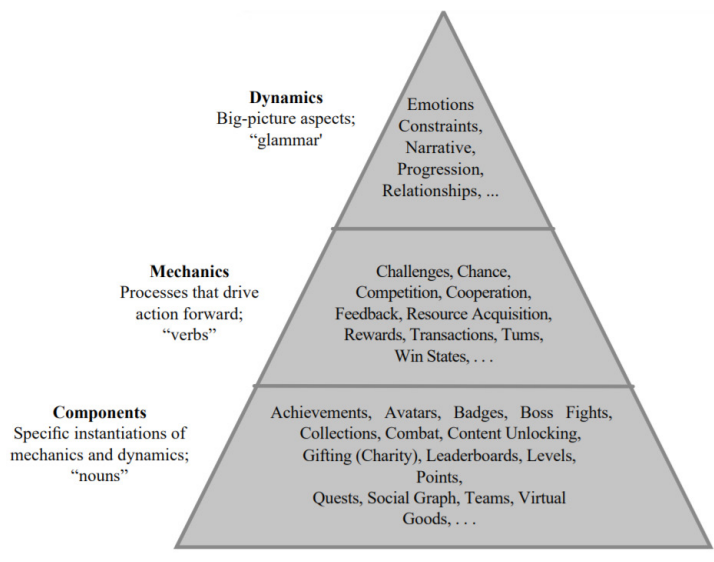

Fig. 1. SD gamification concept [12]

The main implementation of the gamification framework is tools that support it. On the product market, there are already some solutions that allow using gamification in the SD process: DevRPG [13], TEAMFEED [14], Catcher [5] and Gamiware [15]. Summary of the tools have been given in Table II.

TABLE II.

SD GAMIFICATION FRAMEWORKS

\begin{tabular}{|c|c|}
\hline Tool & Description \\
\hline DevRPG [13] & $\begin{array}{l}\text { Goal: Gamification tool is to make the develop- } \\
\text { ment process challenging and fun. The tool was } \\
\text { embedded in the task management tool. } \\
\text { Elements: Rewards, challenges, instant feed- } \\
\text { backs, points, roles. } \\
\text { Advantage: Good metrics to measure perfor- } \\
\text { mance by promoting developer competition. The } \\
\text { feedback from the team shows that everyone was } \\
\text { impressed with their results and made the enthusi- } \\
\text { astic process more active. } \\
\text { Disadvantage: Not mentioned. }\end{array}$ \\
\hline $\begin{array}{l}\text { TEAMFEED } \\
{[14]}\end{array}$ & $\begin{array}{l}\text { Goal: Tool was developed by a team of research- } \\
\text { ers who researched a university course, testing the } \\
\text { use of gamification in the development process, } \\
\text { based on student loyalty. } \\
\text { Elements: Points, leader-boards, comments, feed- } \\
\text { backs. } \\
\text { Advantage: Increases the amount of work done by } \\
\text { developers, encourages more active work. } \\
\text { Disadvantage: Not mentioned. }\end{array}$ \\
\hline Catcher [5] & $\begin{array}{l}\text { Goal: The core functionality of the tool is to } \\
\text { reward programmers for eliminating the code, } \\
\text { which protects the functionality errors and im- } \\
\text { proves the quality of the code. } \\
\text { Elements: Points, reminders. } \\
\text { Advantage: Developers are more motivated to } \\
\text { take action for better code quality. } \\
\text { Disadvantage: Big amount of reminders detract } \\
\text { from work, tension during task execution }\end{array}$ \\
\hline $\begin{array}{l}\text { G a m i w a re } \\
{[15]}\end{array}$ & $\begin{array}{l}\text { Goal: Designed to influence the ability of gami- } \\
\text { fication to explore the motivation of a developer } \\
\text { team. The main elements of the gameplay dynam- } \\
\text { ics are the progress tracking and interpersonal re- } \\
\text { lationships. } \\
\text { Elements: Roles, tasks, feedbacks, leaderboards, } \\
\text { points and levels. } \\
\text { Advantage: Increasing motivation among partici- } \\
\text { pants, faster execution of tasks and better perfor- } \\
\text { mance of tasks. } \\
\text { Disadvantage: Hard process of implementation. }\end{array}$ \\
\hline
\end{tabular}

Components, tools, players, motivators together make gamification framework. Gamification framework 
answers to questions: what is being gamified; why is it gamified; who are the users; how is it being gamified [16]. Multiple frameworks describe the design process [17]. One of them is 6D framework [18] with six elements or steps: define business objectives; define target behaviours; describe you players; devise activity loops; do not forget the fun; deploy appropriate tools.

\section{Software Development Project Gamification FRAMEWORK}

The SD project gamification framework is created with the target to motivate the project team to perform daily project tasks and correctly document tasks status in PM tool.

The framework has been created based on the design steps of gamification design frameworks and SD project team members daily routine tasks classified as boring. Gamification framework has been documented using the gamification canvas model [19]. Fig. 2 describes the main concepts of the SD project gamification framework.

The gamification framework main dynamic is to award with points user after he has performed activities with his assigned task (with other words, status change) according to his project role (programmer, analyst and tester). After a team member individually or team together collects the required amount of points, it can be rewarded with some prize (training or team building event).

Playing elements used in SD gamification framework:

1. Dynamics:

a. progress - point for performed activities;

b. relationships - team unity for goal achievement;

c. limitations - points are given only performing activities related to role.

2. Mechanics:

a. competition - leader board table with each team member points;

b. feedbacks - user see his contribution to the project;

c. prizes - achieving individual and team point goals can be exchanged with a prize;

d. cooperation- only team working together team goal can be achieved;

e. win status - user can see his contribution to project goal achievement.

\section{Components:}

a. points - items user get for his activities. For each activity can be different points;

b. leader boards - user ranking according to earned points;

c. achievement - user goal achievement.

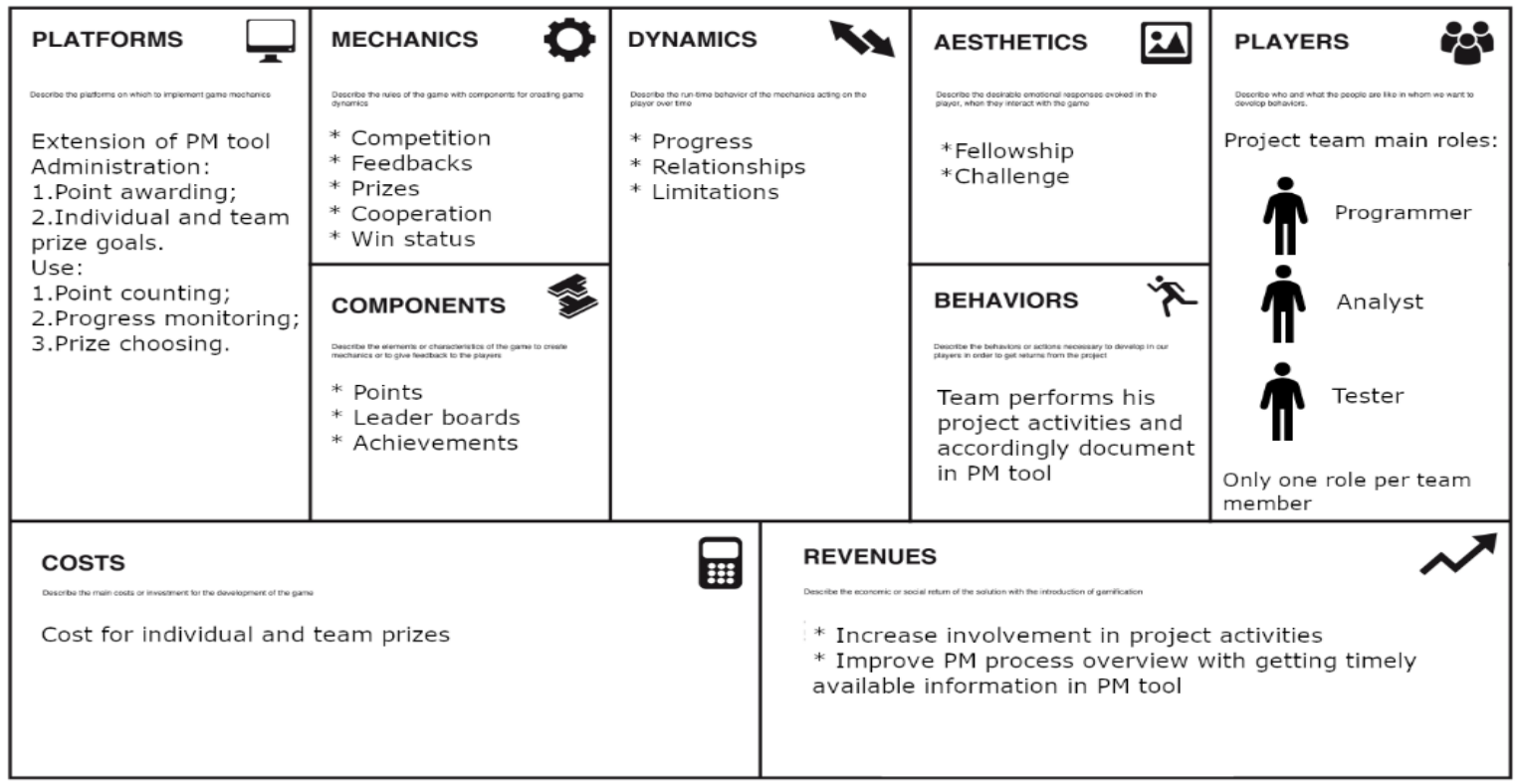

Fig. 2. SD gamification framework canvas model

- The tools that will support the SD gamification framework will be an extension of PM tool. Tool administration section needs to allow set up:

- Work items and workflow status changes performed by a defined role that are awarded to a defined number of points. Can be separately defined for individual goals and project team goals;

Individual and team prizes and their points goals.
IV. THE TOOL FROM USER AND PROJECT PERSPECTIVE NEED TO SUPPORT POINTS COUNTING, PROGRESS MONITORING AND PRIZE CHOOSING AFTER POINT GOAL IS REACHED.

\section{Application and evaluation}

To demonstrate how gamification framework works it has been implemented as the Jira plugin. Gamification process has been connected to Jira project work item types, its workflow statuses and project roles.

- Settings for the SD project gamification tool:

- JIRA project work item types, e.g., user stories, bug, 
task etc., according to the SD process.

- JIRA project workflow that defines work item statuses (e.g., to do, in progress, ready for QA, done, reopened, blocked) and status transactions (Fig.3 A). Need to be defined according to the SD process with correct statuses that the team need to do.

- Point configuration (Fig.3 B) where is defined points (individual and project) what each role earns by moving the task to a certain status.
Prize definition (Fig.3 C) where is configured individual and project prizes with point goals.

The user or team member earning points by doing works and updating Jira tasks status. The user can choose target prize from store (Fig. 3 D), monitor the progress of individual and project goal achievement (Fig. 3 E), and team member results in leader board (Fig. 3 F)

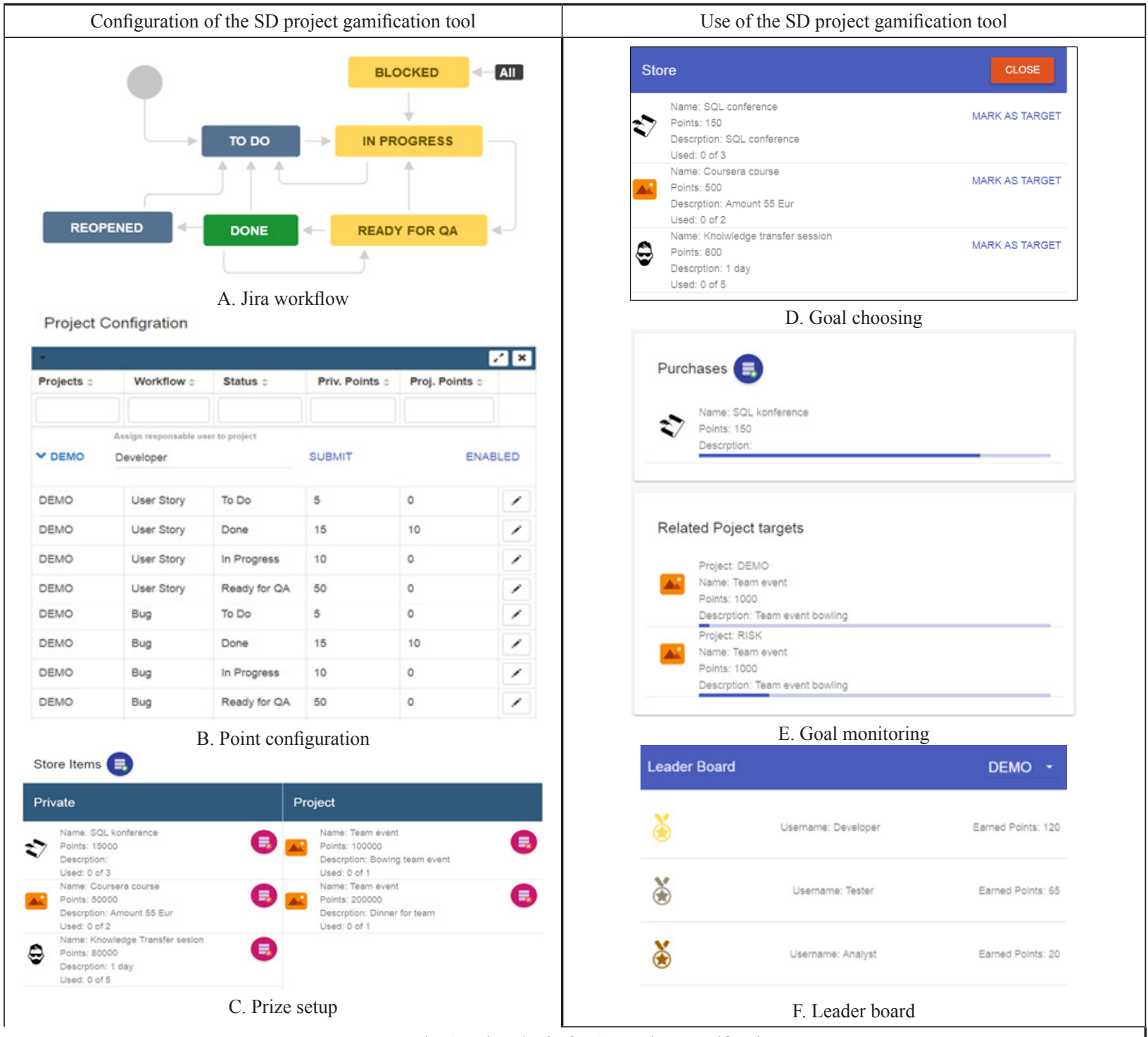

Fig. 3. Jira plugin for SD project gamification

Small focus group testing and survey have been organised to understand how good the SD project gamification framework and its usability is. Focus group consist of three project managers, one tester and one programmer. Focus group members were familiar with Jira and were introduced with gamification principles and the developed SD project gamification framework. All focus group members have a chance to use the Jira plugin. Alter they answered six questions: Benefits of tool usage? Does the tool motivate to gain new knowledge? Does the tool improve team integrity? Does the tool motivate to do daily tasks? Improvements needed? Do you recommend the tool for your team?Focus group evaluated the plugin as easy to use and can reach its objectives. However, the same time highlighted question about correct chose of prizes that is one of the standard questions during gamification framework development [6]. Ideas for the future that were recommended are: give points based on task complexity (story points or estimate) and give points for timely spent time logging.

\section{CONCLUSIONS}

Gamification of the process is one of approach on how to change people behaviours and give more fun in boring activities. With this purpose has been developed SD project gamification framework and its prototype as the Jira plugin. Because of the SD project gamification framework using, the project team member will do they 
work and accordingly update information in PM tool. Motivator for team members to do this in time will be an option to get some individual or team prizes. As a benefit for project manager is not only completed project tasks but the information in PM tool that will show actual progress, bottleneck and problem areas in project processes. Of course, it will require some additional cost from the project budget, but the same time can be reviewed as an investment in team building and project risk mitigation.

As potential future works for this gamification framework extension are: 1) make more complex point awarding dependent of task complexity; 2) award points not only for status changes but other activities - e.g. time logging, feedback giving etc.; 3) introduce more components (e.g. badges) and dynamics.

\section{REFERENCES}

[1] P. Bourque and R. E. Fairley, eds., The Guide to the Software Engineering Body of Knowledge (SWEBOK Guide), 3.0. IEEE Computer Society, 2014.

[2] A. Caccamese and D. Bragantini, "The hidden pyramid," in PMI ${ }^{\circledR}$ Global Congress 2015, Orlando, Florida, USA, PA: Project Management Institute, 2015.

[3] Project Management Institute, A Guide to the Project Manage-

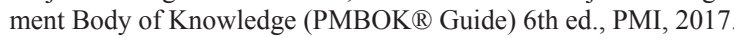

[4] J. Swacha, "Gamification in Enterprise Information Systems: What, Why and How," Proceedings of the 2016 Federated Conference on Computer Science and Information Systems, vol. 8, pp. 1229-1233, Oct. 2016. https://doi.org/10.15439/2016f460

[5] S. Arai, K. Sakamoto, H. Washizaki and Y. Fukazawa, "A Gamified Tool for Motivating Developers to Remove Warnings of Bug Pattern Tools,"2014 6th International Workshop on Empirical Software Engineering in Practice, Nov. 2014. https://doi. org/10.1109/iwesep.2014.17

[6] J. Landsell and E. Hägglund, "Towards a Gamification Framework: Limitations and opportunities when gamifying business processes," Tech. Rep 2016. [Online]. Available: https://umu. diva-portal.org/smash/get/diva2:929548/FULLTEXT01.pdf [Accessed: 04-Mar-2019].
[7] R. Smith, "The future of work is play", в CHI 2013 Workshop "Designing Gamifica-tion", Paris, 2013

[8] "Project Management: How to Motivate Team Members" [Online]. Available: https://www.dummies.com/careers/project-management/project-management-how-to-motivate-team-members/ [Accessed: 04-Mar-2019].

[9] V. Platonova and S. Bērziša, "Gamification in Software Development Projects," Inf. Technol. Manag. Sci., vol. 20, pp. 58-63, 2017. https://doi.org/10.1515/itms-2017-0010

[10] International Institute of Business Analysis, A Guide to the Business Analysis Body of Knowledge (BABOK), 3rd ed., IIBA 2015.

[11] ISQTB "Certified Tester Foundation Level Syllabus, 2018" [Online]. Available: https://www.istqb.org/downloads/send/51-ctfl2018/208-ctfl-2018-syllabus.html [Accessed: 25-Mar-2019].

[12] I R. Management Association, Ed., "Gamification," 2015. https:// doi.org/10.4018/978-1-4666-8200-9

[13] E. B. Passos, D. B. Medeiros, P. A. S. Neto and E. W. G. Clua, "Turning Real-World Software Development into a Game," 2011 Brazilian Symposium on Games and Digital Entertainment, Nov. 2011. https://doi.org/10.1109/sbgames.2011.32

[14] L. Singer and K. Schneider, "It was a Bit of a Race: Gamification of Version Control," 2012 Second International Workshop on Games andSoftware Engineering: Realizing User Engagement with Game Engineering Techniques (GAS), Jun. 2012. https://doi. org $/ 10.1109 /$ gas.2012.6225927

[15] T. Barik, E. Murphy-Hill and T. Zimmermann, "A Perspective on Blending Programming Environments and Games: Beyond Points, Badges, and Leaderboards," 2016 IEEE Symposium on Visual Languages and Human-Centric Computing (VL/HCC), Sep. 2016. https://doi.org/10.1109/vlhcc.2016.7739676

[16] A. Marczewski, "A Simple Gamification Framework / Cheat Sheet." 2012. [Online]. Available: https://www.gamified.uk/gamification-framework/ [Accessed: 25-Mar-2019].

[17] D. Riera, J. Arnedo-Moreno, A. Mora, and C. González, "A literature review of gamification design frameworks,", 7th International Conference on Games and Virtual Worlds for Serious Applications (VS-Games), no. April 2015, 2015. https://doi.org/10.1109/ VS-GAMES.2015.7295760

[18] K. Werbach and D. Hunter, For the win: how game thinking can revolutionize your business. Wharton, 2012.

[19] "Gamification model canvas" [Online]. Available: http://www. theloyaltygames.com/wp-content/uploads/2014/07/gamification model canvas.pdf [Accessed: 25-Mar-2019]. 